\title{
PHYSICO-CHEMICAL CHARACTERISTICS AND FIELD PERFORMANCE IMPROVEMENT OF THE (IGR) ATABRON
}

\author{
IBRAHIM, N. A. ${ }^{1}$ AND SONDOS A. MOHAMED ${ }^{2}$ \\ 1 Central Agricultural Pesticides Lab., ARC, Dokki, Giza \\ 2 Plant Protection Research Institute, ARC, Dokki, Giza
}

(Manuscript received 18 August 2008)

\begin{abstract}
It well known that there is a clear relation between the Physico-chemical characteristics of used pesticides and their field performance. As a result, the international organizations (FAO and WHO) outlined the tests and specifications that each pesticide must be pass in laboratory before field application. In this study tests were conducted to improve the physico-chemical properties of the IGR atabron 5\% EC that was imported, on the account of the Ministry of Agriculture in 2005 but it failed in laboratory tests. These treatments were carried out by using locally available additives as organic solvents and surface active agents. We found that emulsifier (Tween 80 ) or its mixture with the polar solvent DMF highly improved the Physico-chemical characteristics of the insecticide. Field performance evaluation was carried out for the reworked and non-reworked formulations in the season of 2007. The data obtained revealed that the selected two methods of treatment clearly improved the insecticidal activity under field conditions.
\end{abstract}

\section{INTRODUCTION}

Synthetic organic pesticides are important component of the modern agriculture (Meller and Admas 1984 and Croft 1990). One class of these chemicals is the insect growth regulators (IGRs) that disrupt and impede the life cycle of insects. So, many formulated and commercially available IGR products are used in Egypt such as Atabron 5\% EC which was reported to be the most efficient one in Egypt (El Ghareeb 1992, Khedr et al. 2005). On the other hand, the efficiency of the final pesticidal spray solutions in the field is strongly correlated with their physico-chemical characteristics (Furmidge 1962). As a results, quality control work, research and development, as well as laboratory tests are the most decided factors for the pesticides efficiency before conducting extensive field trials. Consequently, the international organizations (FAO and WHO, 2006) outlined the tests and specifications that each type of formulation must be pass successfully to achieve its target action in the field. The present work has two main targets. The first is the using of some local additives to improve the physico-chemical properties of the pesticide Atabron 5\% EC that is imported on the account of the Ministry of Agriculture and Land Reclamation in 2005 and failed to achieve the required tests and specifications. The second is the 
field evaluation of the treated and untreated formulations to investigate the effect of additives on the pesticide field performance.

\section{MATERIALS AND METHODS}

\section{Insecticide used:}

Atabron 5\% EC (IGR) produced by syngenta Agro Switzerland and imported by syngenta Agro Egypt.

- $\quad$ It is used at the rate of $400 \mathrm{ml} /$ feddan.

Chemical structure:<smiles>O=CNc1cc(Cl)c(Oc2ncc(C(F)(F)F)cc2Cl)c(Cl)c1</smiles>

IUPAC name:

1- [3,5-dichloro-4-(3-chloro-5-trifluoromethyl-2-pyridyloxy) phenyl] -3- (2,6- difluorobenzoyl) urea.

- Comman name: Chlorfluazuran

\section{Additives used:}

Locally produced organic solvents such as ethanol, isobutanol, toluene, xylene, dimethylformamide (DMF), cyclohexanone and the surface active agent tween 80 ( $\left.T_{80}\right)$ which were produced by EL Nasr pharm. chem. Co., Abu Zaabal, Egypt.

\section{Physico-chemical properties determination}

Physical properties for treated, untreated insecticide and their spray solutions were determined as follows: $\mathrm{pH}$ value using Schott Gerate $\mathrm{pH}$ meter, viscosity using brookfield viscometer and surface tension using surface tensiomate, cole parmer. Conductivity and salinity were measured using the conductometer YSI model 33 S-CT. Tropical storage, cold test as well as free acidity and alkalinity were determined according to the specifications of WHO (1979). Active ingredient content was determined using HPLC of UV detector, mobile phase is acetonitrile - water (80:20) mixture at wave length $254 \mathrm{~cm}$.

\section{Pesticidal efficiency evaluation against cotton leafworm.}

The experiment was conducted according to the Ministry of Agriculture protocol (1993) for determination the activity of anti-molting agents (IGRs) against cotton leafworm. Field- laboratory experiment was carried out in cotton plant cultivated in Giza governorate at Plant Protection Research Institute (PPRI) from season of 2007 using knapsack sprayer for all treatments. One treatment was left without spraying as a control. Random leaf samples were collected directly after spraying when plant became dry for studying the initial effect and after 7 days of application for studying 
the residual effect against the $2^{\text {nd }}$ and $4^{\text {th }}$ instar larvae of cotton leafworm under laboratory conditions.

Three replicates for each treatment were carried out, each has 15 larvae. Mortality counts were recorded after 2 days of introducing leaves. For studying the latent effect, untreated cotton leaves were taken continuously and introduced to the rest alive larvae till pupation. Mortality counts were recorded after 5 days of the start and every 3 days up to pupation. Mortality percentages were recorded then corrected according to Abbot formula (1925). Total mortality percentage after 5 days of treatment is considered as the initial effect of the tested materials while, the total percentage of kill up to pupal stage is considered as the latent effect.

\section{RESULTS AND DISCUSSION}

\section{Improvement the physico-chemically characteristics of the IGR Atabron} 5\% EC.

It is a well known fact that, the stability of the emulsion in the spraying has a great effect on the uniformity of spray application and the field performance so it is the most important test for emulsifable concentrate formulations before the field application stage. Data in Table (1) show that emulsion stability test or creamy layer separation in formulation (B) is more than $2.0 \mathrm{ml}$ so this patch failed in laboratory tests.

Table 1. The main physico-chemical properties of Atabron 5\% EC.

\begin{tabular}{|ll|c|c|}
\hline \multicolumn{2}{|c|}{ Properties before accelerated hot storage } & Formulation $(\mathrm{A})$ & Formulation (B) \\
\hline $1-$ & The \% of active ingredient & 4.89 & 4.85 \\
$2-$ & Free acidity $\left(\right.$ as $\left.\mathrm{H}_{2} \mathrm{SO}_{4}\right)$ & 0.0059 & 0.0068 \\
$3-$ & Emulsion stability $(\mathrm{ml})$ & 1.7 & 4.3 \\
\hline Properties after accelerated hot storage & & \\
\hline 1- & The \% of active ingredient & 4.78 & 4.80 \\
2- & Free acidity $\left(\right.$ as $\left.\mathrm{H}_{2} \mathrm{SO}_{4}\right)$ & 0.0078 & 0.0068 \\
& 3- Emulsion stability $(\mathrm{ml})$ & 2.0 & 4.9 \\
\hline
\end{tabular}

- Formulation $(A)$ is the standard formulation i.e passes emulsion stability test in lab.

- Formulation (B) failed in emulsion stability test without treatment.

Data presented in Table (2) show the emulsion stability test of the used IGR alone and with different additives. It is obvious that, high creamy layer separation was obtained for the insecticide alone especially in hard water (H.W). Data also show that solvents added were moderately improved the emulsion stability test where the creamy layer decreases as the polarity of solvent increases. Accordingly, the lowest creamy separation was obtained by using the highest polar solvent dimethylformamide (DMF). In addition, using the emulsifier tween $80\left(T_{80}\right)$ by the same rate of addition ( $2 \%$ ) produced the highly stable emulsion upon dilution with 
three types of water. Data also show that methods of reworking 10 and 11 are the best as the creamy separation was reduced to traces or zero.

Table 2. Effect of additives (2\%) on the emulsion stability of the IGR Atabron 5\% EC.

\begin{tabular}{|c|c|c|c|c|c|}
\hline \multirow{2}{*}{ Method of treatment } & \multirow{2}{*}{ Additives } & \multirow{2}{*}{ Appearance } & \multicolumn{3}{|c|}{ Creamy layer separation $(\mathrm{ml})$} \\
\cline { 4 - 6 } & & & H.W & S.W & T.W \\
\hline 1 & ----- & Not milky & 5.0 & Traces & 0.0 \\
\hline 2 & Toluene & Not milky & 2.7 & 1.5 & Traces \\
\hline 3 & Xylene & Not milky & 2.7 & 1.5 & Traces \\
\hline 4 & Ethanol & Not milky & 2.5 & 1.5 & Traces \\
\hline 5 & isobutanol & Not milky & 2.5 & 1.0 & Traces \\
\hline 6 & Cyclohescanone & Not milky & 2.1 & 0.5 & Traces \\
\hline 7 & DMF & Not milky & 1.0 & 0.5 & 0.0 \\
\hline 8 & DMF+T $_{80}(1: 1)$ & Milky & 1.0 & Traces & 0.0 \\
\hline 9 & DMF+ T $_{80}(4: 6)$ & Milky & 0.8 & Traces & 0.0 \\
\hline 10 & $\mathrm{DMF}_{80}(3: 7)$ & Milky & Traces & Traces & 0.0 \\
\hline 11 & $\mathrm{~T}_{80}$ & Milky & 0.0 & 0.0 & 0.0 \\
\hline
\end{tabular}

H.W is the hard water S.W is the soft water T.W is the tap water

Data in Table (3) show that some physical properties as creamy separation, $\mathrm{pH}$ value, salinity and conductivity were changed remarkably according to the type of water used for dilution but the other properties were slightly changed. It is shown that the creamy separation property was the highly effected and improved property where the precipitation was reduced from $5.0 \mathrm{ml}$ to traces or zero. Many benefits can be obtained from this change such as avoiding phytotoxicity of the treated plants, due to precipitation of the active materials, and the uniformity of the spray application that improves the pesticidal efficiency.

Fig 1. Effect of additives on the creamy layer separation property of Atabron $5 \%$ EC in H.W.

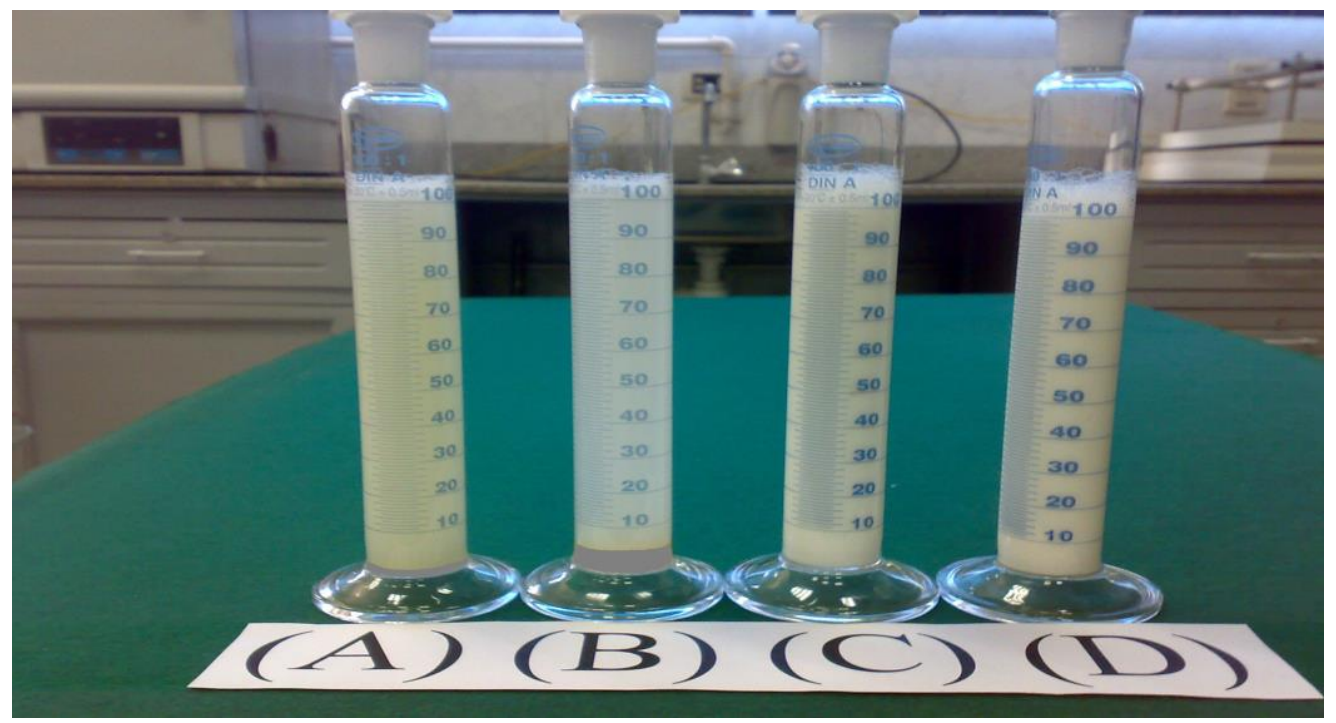

- Formulation $(A)$ is the standard formulation i.e passes emulsion stability test in lab.

- Formulation (B) failed in emulsion stability test without treatment.

- Formulation (C) failed in emulsion stability test and treated by method 11 .

- Formulation (D) failed in emulsion stability test and treated by method 10 . 
Fig (1) shows the effect of additives (methods 10 and 11) on the emulsion stability as well as creamy layer separation of spray solutions of four formulations in hard water. The pesticide emulsion becomes milky and the creamy layer separation was reduced to nil. Laboratory investigation showed that the active ingredient contents were not affected by additives before and after cold as well as accelerated hot storage tests. They were found to be $5.0 \pm 0.2 \%$ which meets the WHO specifications. As the physico-chemical properties of the pesticide spray solutions in tap water and soft water are nearly the same but different from that in hard water, we evaluated the insecticidal efficiency in field, at the field application rate, using tap water and hard water for dilution.

Table 3. Effect of additives on the physico-chemical prosperities of Atabron spray solution.

\begin{tabular}{|c|c|c|c|c|c|c|c|c|}
\hline Formulation & $\begin{array}{l}\text { Water of } \\
\text { dilution }\end{array}$ & $\begin{array}{l}\text { Foam } \\
\text { (cm) }\end{array}$ & $\begin{array}{c}\text { Creamy } \\
\text { separation } \\
(\mathrm{ml})\end{array}$ & $\begin{array}{c}\mathrm{PH} \\
\text { valu } \\
\mathrm{e}\end{array}$ & $\begin{array}{l}\text { Salinit } \\
\text { y (\% } \\
0)\end{array}$ & $\begin{array}{l}\text { Conductivity } \\
\qquad(\mu \mathrm{s})\end{array}$ & $\begin{array}{l}\text { Surface } \\
\text { tension } \\
\text { (dyne/cm) }\end{array}$ & $\begin{array}{l}\text { Viscosity } \\
\text { (cm poise) }\end{array}$ \\
\hline \multirow{3}{*}{ A } & T. W & 27 & 0.0 & 6.65 & 0.3 & 548 & 32.5 & 2.27 \\
\hline & H. W & 30 & Traces & 4.27 & 0.1 & 202 & 31.5 & 2.22 \\
\hline & S. W & 10 & 2.0 & 4.56 & 0.4 & 782 & 33.0 & 2.26 \\
\hline \multirow{3}{*}{ B } & T. W & 28 & Traces & 6.28 & 0.2 & 450 & 33.5 & 2.28 \\
\hline & H. W & 31 & Traces & 4.05 & 0.1 & 212 & 33.5 & 2.21 \\
\hline & S. W & 5 & 3.5 & 4.13 & 0.4 & 776 & 34.0 & 2.23 \\
\hline \multirow{3}{*}{ C } & T. W & 33 & Traces & 6.53 & 0.2 & 443 & 34.0 & 2.17 \\
\hline & H. W & 35 & Traces & 3.94 & 0.1 & 204 & 33.5 & 2.19 \\
\hline & S. W & 11 & Traces & 4.07 & 0.4 & 779 & 33.5 & 2.22 \\
\hline \multirow{3}{*}{ D } & T. W & 25 & Traces & 6.63 & 0.2 & 437 & 33.0 & 2.24 \\
\hline & H. W & 33 & 0.0 & 4.27 & 0.1 & 201 & 33.7 & 2.21 \\
\hline & S. W & 31 & 0.0 & 4.45 & 0.4 & 781 & 33.0 & 2.22 \\
\hline
\end{tabular}

\section{Field performance evaluation:}

\section{1- Insecticidal activity against the $\mathbf{2}^{\text {nd }}$ instar larvae.}

Results in Table (4) indicated that, the mortality percentage increases as the period of exposure increases. Initial kill, after 5 days of treatment, was high for all treatments in tap water (T.W) than in hard water (H.W). Formulation (B), which failed in emulsion stability test, possessed the least percentage of mortality, while the reworked formulations (C) followed by (D) showed the highest activity than formulation (A) which passed successfully in the emulsion stability test in H.W. The same table also showed that the latent effect of the reworked formulation (C) gave 
$100 \%$ mortality in both T.W and H.W followed by the reworked formulation (D) which gave $100 \%$ mortality in H.W only as compared with the standard formulation (A) which gave $90.2 \%$ and $83.0 \%$ in T.W and H.W respectively. On the other hand, formulation (B) gave the least showing $84.2 \%$ in T.W and $78.9 \%$ kill in H.W.

Results in the same Table represents the residual effect of the studied formulations after one week of application. Data of the residual effect showed that much decrease in activity than after direct spraying. This decrease seemed to be higher in (T.W) than in (H.W). Also, it was noted that the initial and latent effects, in H.W proved higher than that in T.W. In all cases the reworked formulations (C) and (D) possessed higher initial as well as latent effects then the formulation (B) and in some cases more than the standard formulation $(A)$. Toxicity lines that represent the data in Table (4) are shown in Fig (2-5).

Table 4. Mortality percentage of the $2^{\text {nd }}$ instar larvae of cotton leafworm spodoptera littoralis.

\begin{tabular}{|c|c|c|c|c|c|c|c|c|}
\hline \multirow{2}{*}{\begin{tabular}{c} 
Period of $\begin{array}{c}\text { exposure } \\
\text { (days) }\end{array}$ \\
\cline { 2 - 10 }
\end{tabular}} & \multicolumn{8}{|c|}{ T. W } \\
\cline { 2 - 9 } & A & B & C & D & A & B & C & D \\
\hline 2 & 25.8 & 19.1 & 32.6 & 20.0 & 21.3 & 23.6 & 25.8 & 24.7 \\
\hline 5 & 62.7 & 49.1 & 75.3 & 47.4 & 39.0 & 52.5 & 66.1 & 59.3 \\
\hline 8 & 73.6 & 66.5 & 87.1 & 69.7 & 57.1 & 74.0 & 100.0 & 100.0 \\
\hline 11 & 90.2 & 84.2 & 100.0 & 91.2 & 83.0 & 78.9 & 100.0 & 100.0 \\
\hline \multicolumn{8}{|c|}{ Residual effect after one week of application } \\
\hline 2 & 21.1 & 15.5 & 14.4 & 3.3 & 11.1 & 8.9 & 6.7 & 13.4 \\
\hline 5 & 28.1 & 19.3 & 22.1 & 10.0 & 29.8 & 22.8 & 26.3 & 33.4 \\
\hline 8 & 29.6 & 29.6 & 41.5 & 31.4 & 54.5 & 36.5 & 45.4 & 52.8 \\
\hline 11 & 36.7 & 33.7 & 59.2 & 38.8 & 60.0 & 52.4 & 63.3 & 57.9 \\
\hline
\end{tabular}

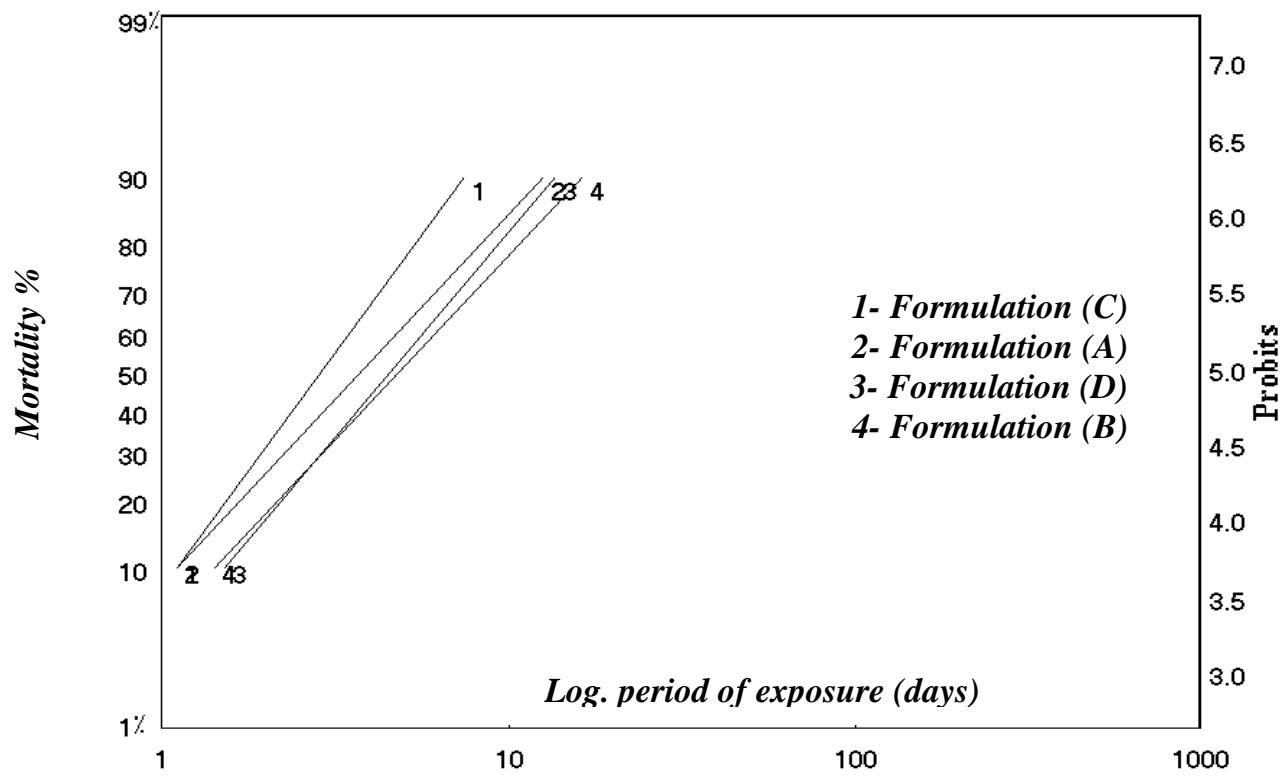

Fig 2. Toxicity lines of four formulations in T.W after direct application. 


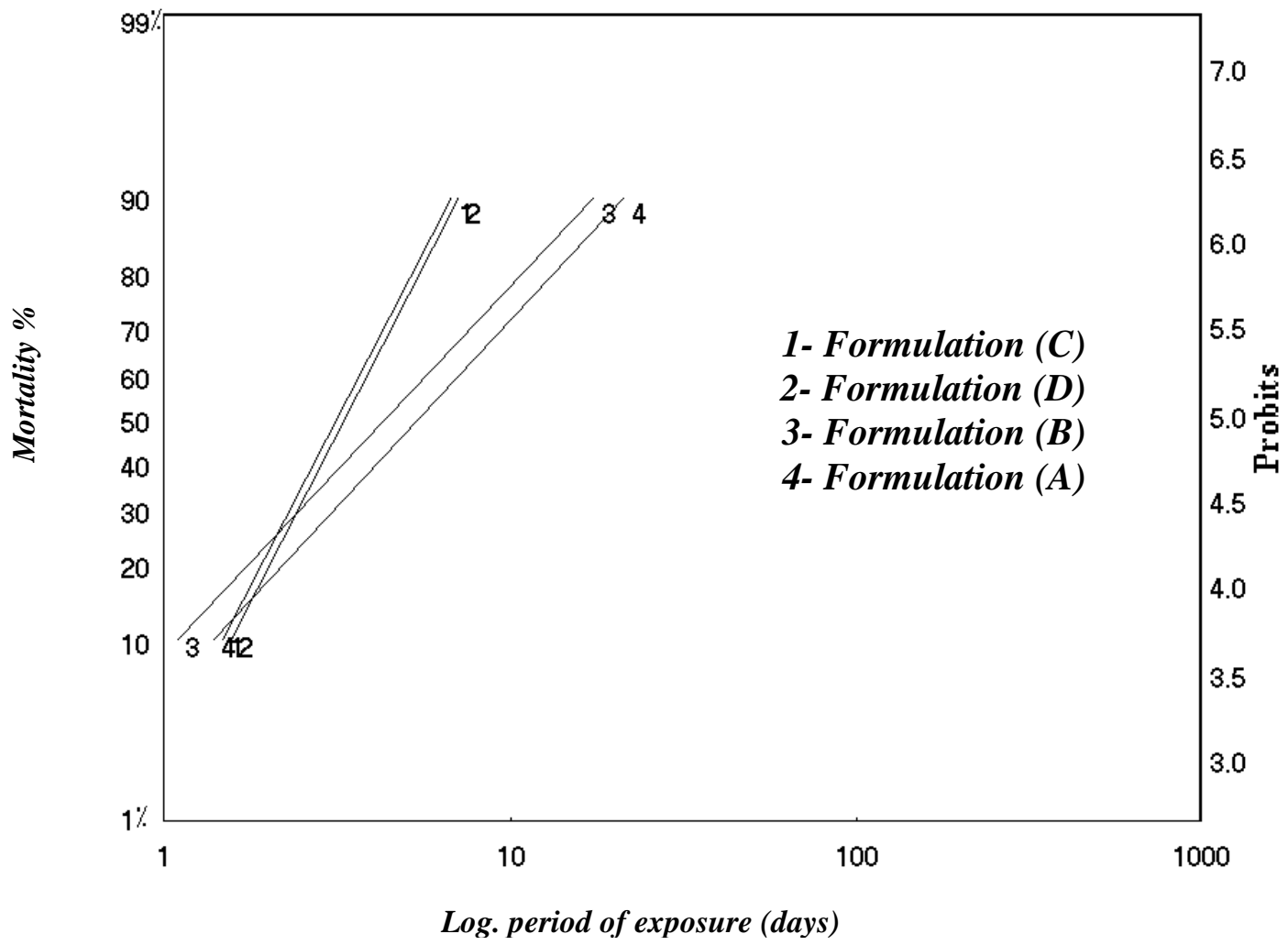

Fig 3. Toxicity lines of four formulations in H.W after direct application.

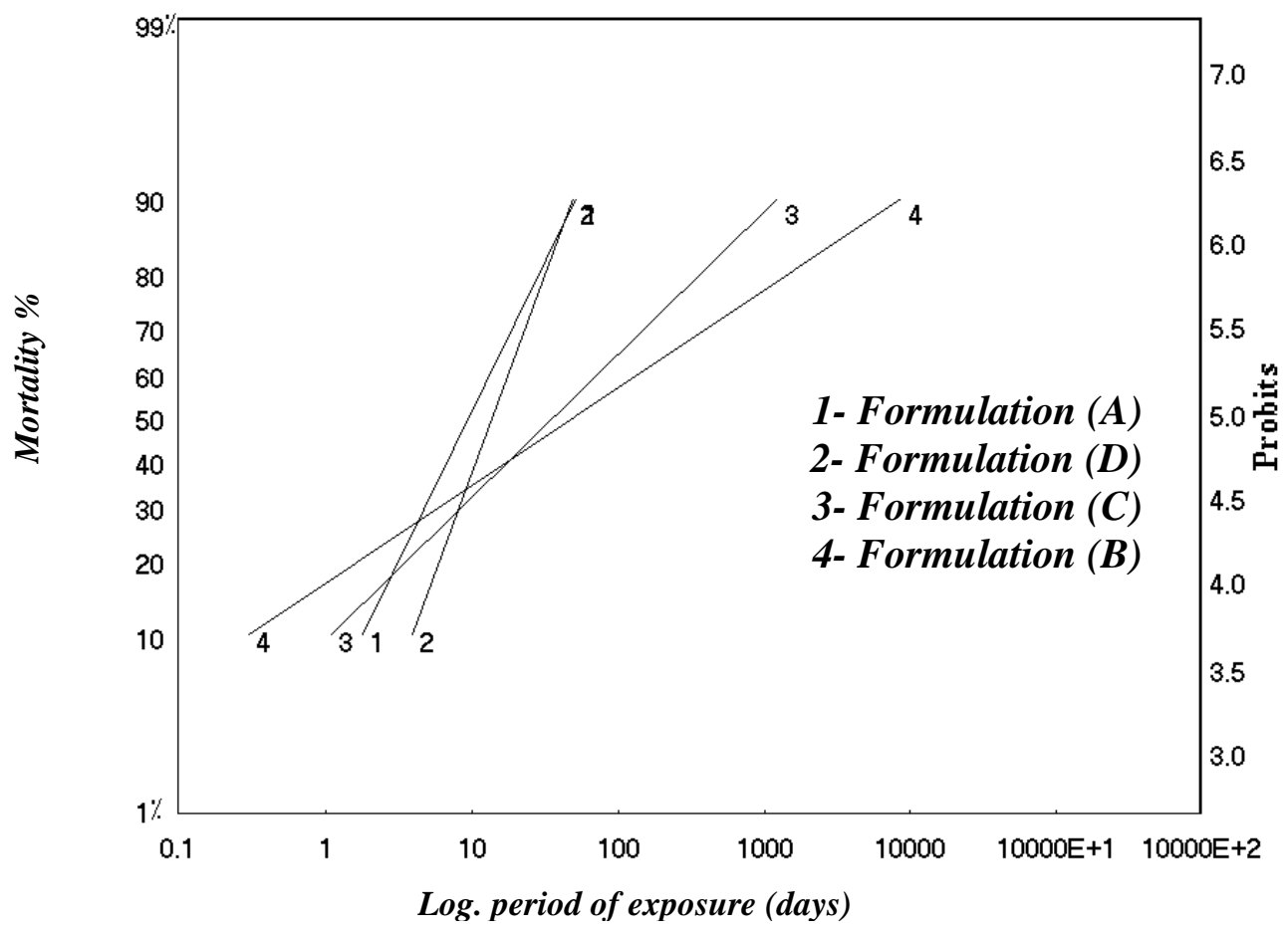

Fig 4. Toxicity lines of four formulations in T.W after one week of application. 


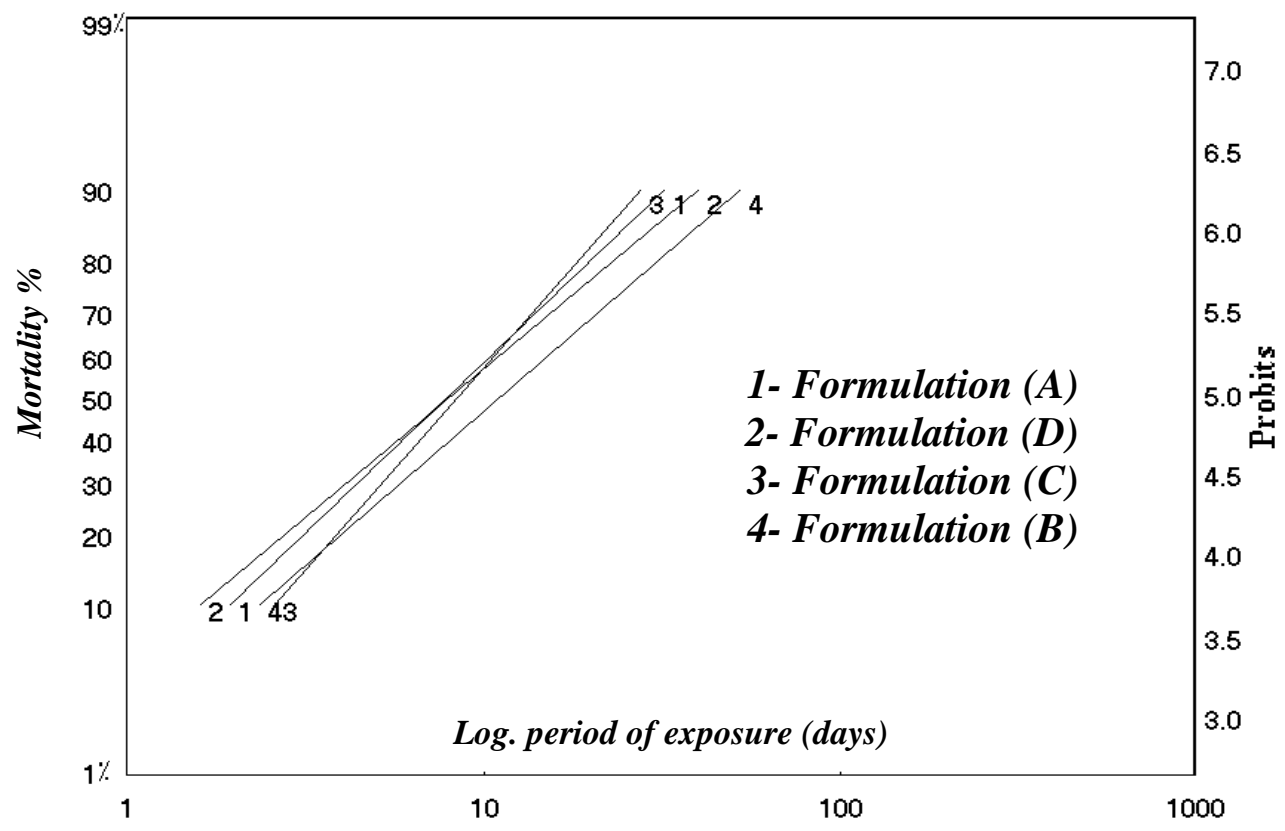

Fig 5. Toxicity lines of four formulations in H.W after one week of application.

\section{2-Insecticidal activity against the $4^{\text {th }}$ instar Larvae.}

Data in table (5) represents the anti-molting activity of four studied formulations against the $4^{\text {th }}$ instar larvae of the cotton leaf worm spodoptera littoralis. It was clear that, both initial and latent effects of four formulations in H.W are more than that in T.W either in case of direct application or in residual activity study. As usual formulation (B) possessed the least mortality percentages in most of tested treatments especially in case of H.W. On the other hand, formulation (C) followed by formulation (D) possessed the highest activity in case of direct spraying and residual effect study irrespective to the type of water used in dilution.

From data represented in Tables (4) and (5), it was noted that the anti-molting activity of all formulations in the field against $2^{\text {nd }}$ instar larvae is more effective than that of the $4^{\text {th }}$ instar larvae. This results is in agreement with that reported by Badr (2000) when he fed the cotton leaf worm on cotton leaves sprayed with the (IGR) consult $10 \%$ EC at 5 and 10 days after spraying. Toxicity lines that represent the data in Table (5) are shown in Fig (6-9). 
Table 5. Mortality percentage of the $4^{\text {th }}$ instar larvae of cotton leafworm spodoptera littoralis.

\begin{tabular}{|c|c|c|c|c|c|c|c|c|}
\hline \multirow{2}{*}{$\begin{array}{c}\text { Period of } \\
\text { exposure } \\
\text { (days) }\end{array}$} & \multicolumn{7}{|c|}{ Insecticidal activity of formulations after direct application } \\
\cline { 2 - 10 } & A & B & C & D & A & B & C & D \\
\hline & 13.4 & 5.0 & 16.0 & 10.0 & 30.7 & 23.8 & 34.4 & 33.0 \\
\hline 2 & 24.2 & 22.4 & 27.6 & 25.9 & 65.5 & 49.3 & 72.7 & 56.9 \\
\hline 5 & 64.1 & 46.1 & 63.3 & 51.1 & 79.0 & 76.1 & 84.1 & 80.3 \\
\hline 8 & 72.9 & 68.6 & 85.4 & 69.6 & 92.1 & 85.5 & 96.2 & 91.6 \\
\hline 11 & & & Residual effect after one week of application & \\
\hline & 12.5 & 8.6 & 15.4 & 11.7 & 20.4 & 15.4 & 30.7 & 26.2 \\
\hline 5 & 22.2 & 14.8 & 25.9 & 16.3 & 50.6 & 37.0 & 48.8 & 48.3 \\
\hline 8 & 29.6 & 22.2 & 43.3 & 20.7 & 66.6 & 56.3 & 80.0 & 68.2 \\
\hline 11 & 40.0 & 33.3 & 57.8 & 37.7 & 82.3 & 70.6 & 90.0 & 78.7 \\
\hline
\end{tabular}

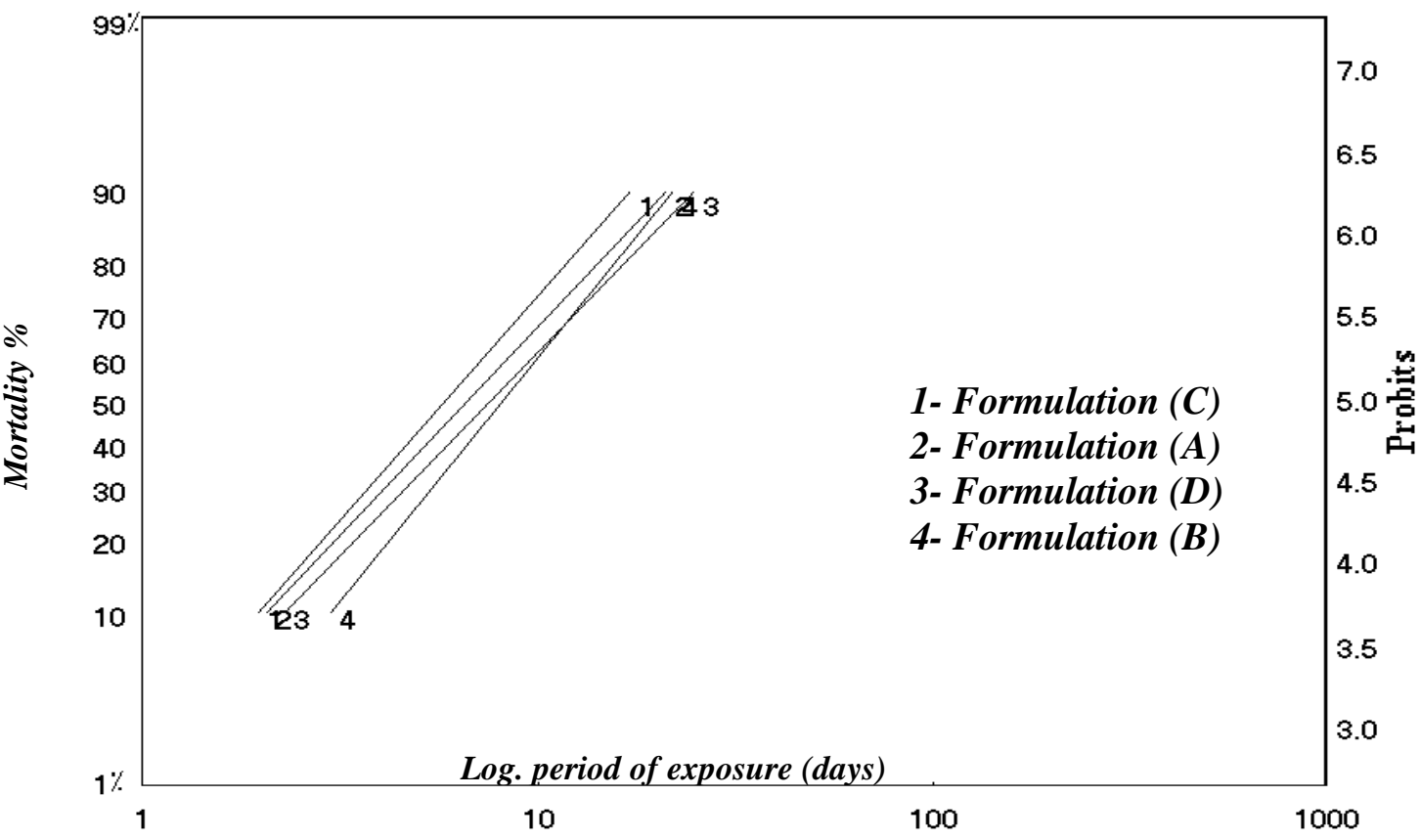

Fig 6. Toxicity lines of four formulations in T.W after direct application. 


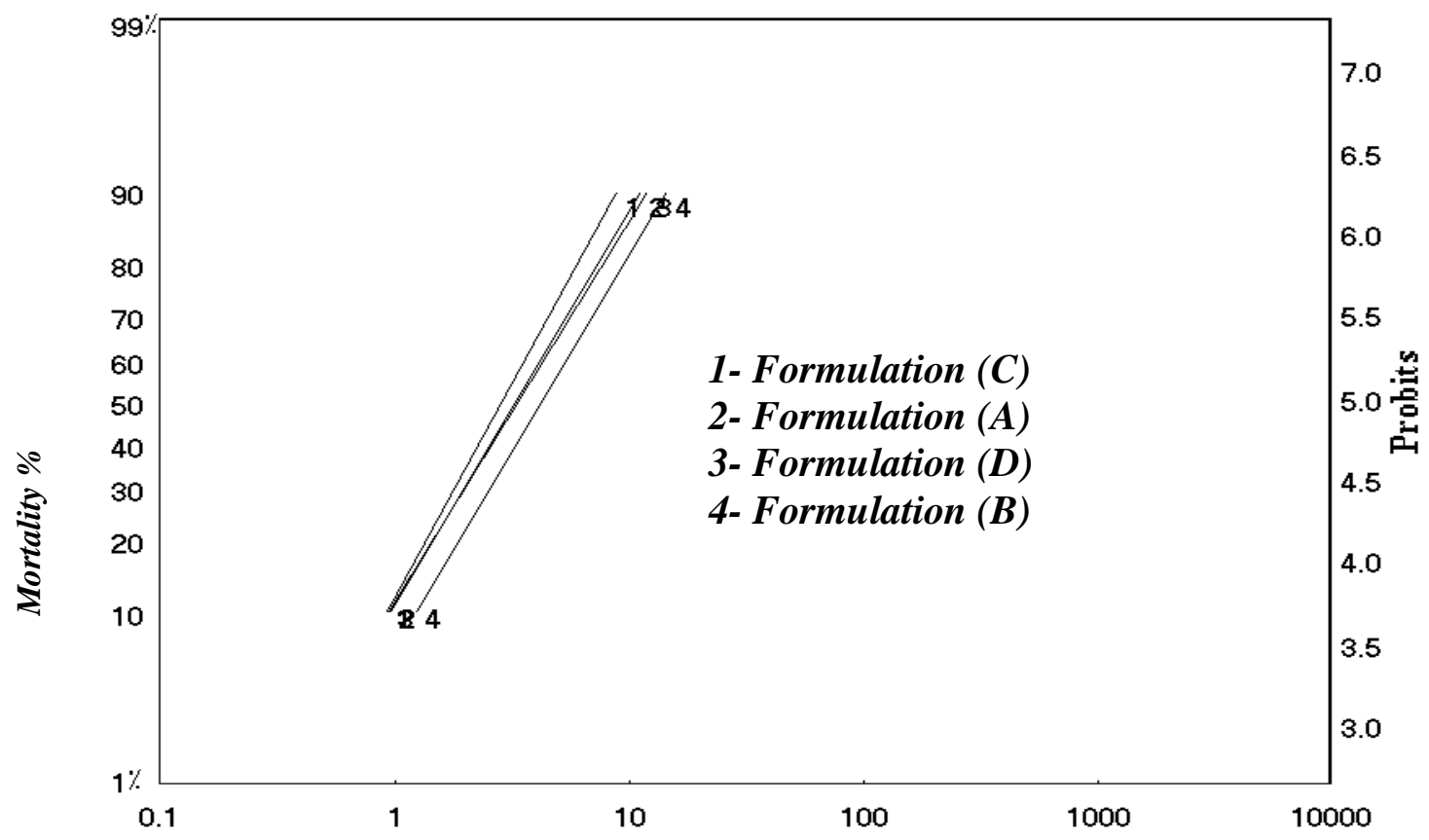

Log. period of exposure (days)

Fig 7. Toxicity lines of four formulations in H.W after direct application.

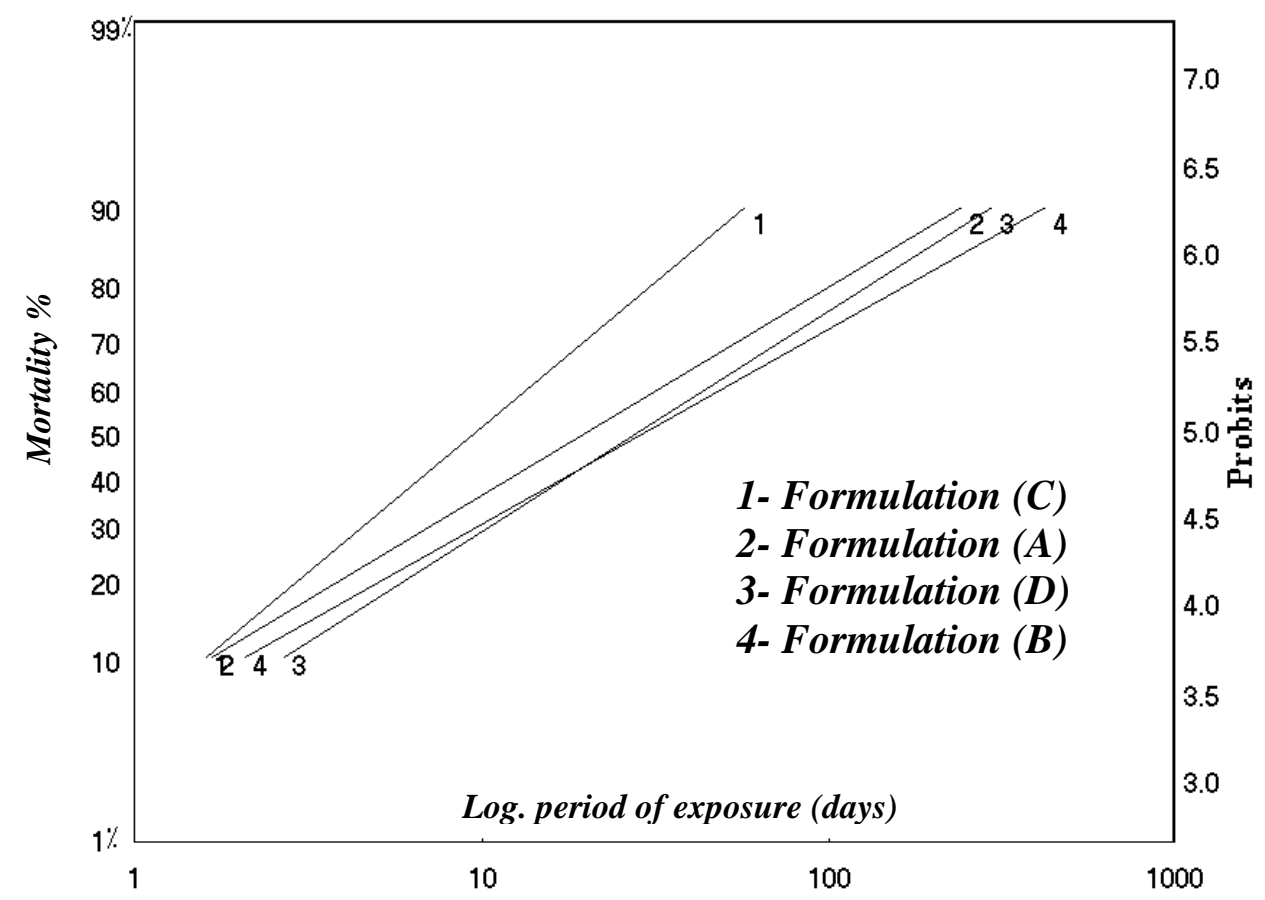

Fig 8.Toxicity lines of four formulations in T.W after one week of application. 


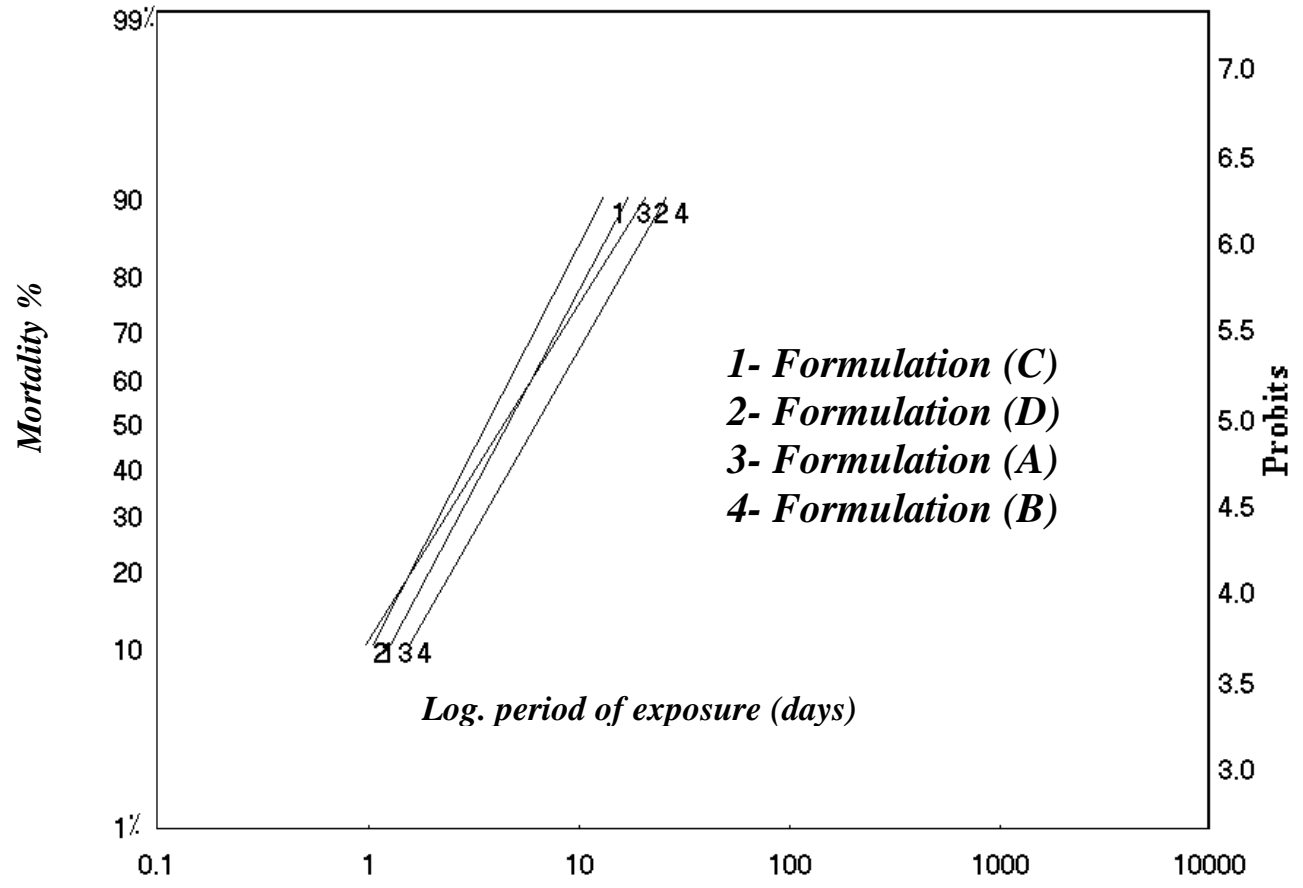

Fig 9. Toxicity lines of four formulations in H.W after one week of application.

\section{Conclusion:}

There are a good correlation between the physico-chemical properties of the (IGR) Atabron 5\% EC and its insecticidal efficiency.

- $\quad$ Formulation (B), which failed in emulsion stability test in laboratory, was reworked to improve its physico-chemical properties using many organic solvents and surface active agent.

The best method of reworking is the using of the emulsifier tween 80 or its mixture with the high polar solvent DMF.

These methods were actually applied to rework about 200 tons of atabron $5 \%$ EC supplied from syngenta Agro- Switzerland on the account of the Ministry of Agriculture and failed in the physico- chemical tests in laboratory.

Field performance evaluation data showed that, the insecticidal activity of the reworked formulations (C) and (D) were higher than that of the non-reworked formulation (B).

Depending on the type of water, used in dilution, it was found that all formulations showed higher activity in H.W than in T.W. 


\section{REFERENCES}

1. Abbott, W. S. 1925. A method of computing the effectiveness of an insectide. J. Econ. Ent., 18: 265- 267.

2. Badr, N. A. 2000. Efficiency of some natural products and insect growth regulator, consult, against the cotton leafworm spodoptera littoralis (Boisd). Egypt. J. Appl. Sci., 15 (9): 316- 327.

3. Croft, B. A. 1990. Arthropod biological control agents and pesticides. pp. 194-287. In: R.L. Metcalf and W. Stumm (Eds.), Environmental Science and Technology, Wiley, New York.

4. El- Ghareeb, A. M. 1992. Comparative toxicity of some bezoylpheyl uarea molt inhibiting insecticides to cotton leaf worm spodoptera littoralis (Boisd). Indian, J. Ent., 54(4): 388- 393.

5. FAO and WHO joint meeting on pesticides specifications (JMPS) 2006. [Manual on Development and Use of FAO and WHO Specifications for Pesticides], Rome.

6. Furmidge. C. G. L. 1962. physico-chemical studies on agricultural sprays. J. Sc: Food Agric., 13: 27- 140.

7. Khedr, M. M. A, W. H. Desuky, S. M. A. EL- Shakaa and S. I. Y. Khalil. 2005. Toxicological and Biochemical studies on the effect of some insect growth regulators on spodoptera littoralis (Boisd) larvae. Egypt. J. Agric. Res. 83. (2). 539- 561.

8. Meller, J. W. and R. H. Adams. 1984. Feeding the under developed world. Chem. Eng. News. 62: 32-39.

9. Ministry of Agriculture. 1993. Protocols of evaluation the pesticides efficiency in Egyptian cultures, pp 85.

10. World Health Organization. 1979. Specifications for Pesticides Used in Public Health, Geneva. 


\section{تحسين الخواص الطبيعية والكفاءة الحقليه لمنظم}

\section{النمو الحثرى أتابرون}

\section{ناصر عبدالمنعم أبراهيم' ، سندس عبدالتواب محمد`}

$$
\text { r ا ـ المعدل المركزى للمبيدات- مركز البحوث الزراعيه- الدقى - جيزة }
$$

من المعروف أن هناك علاقه وثيقه بين الكفاءة الحفليه لمستحضرات مبيدات الآفات الزراعيه وخواصها

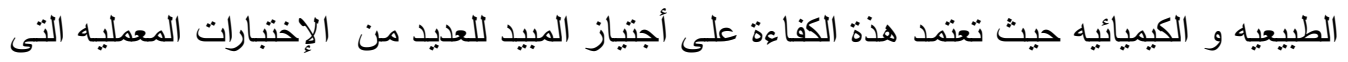

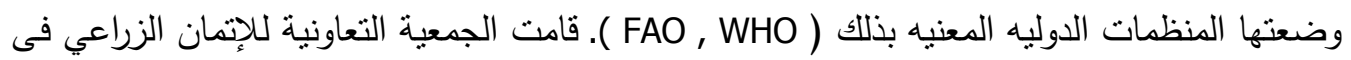

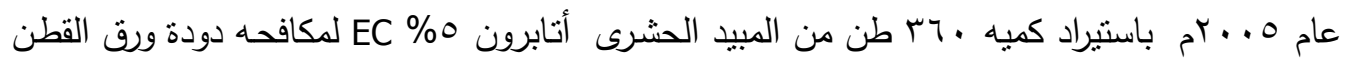

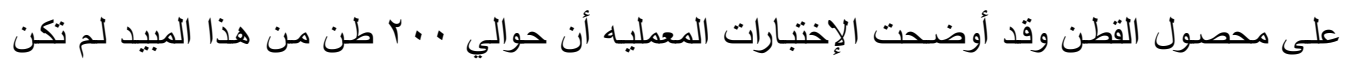

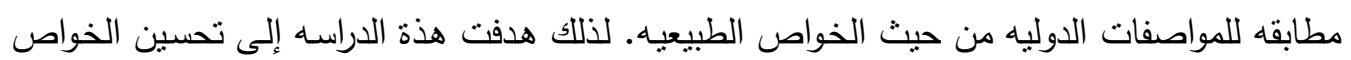

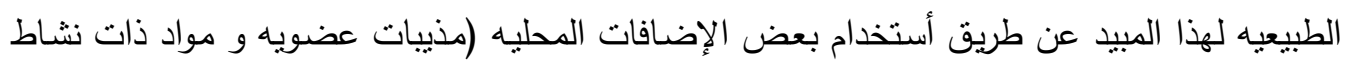
سطحى). وقد أوضحت النتائج المتحصل عليها أن إأضافه المادة ذات النشاط السطحى 80 أو 8 أو مخلوطها مع المذيب العضوى DMF قد حسنت الخواص الطبيعيه بشكل كبير حيث أنها قللت الفصل الكريمى للمبيد فى الماء العسر (H.W ) من ه مل إلى صفر ، وبتقييم الكفاءة الحقليه للمبيد المعالج

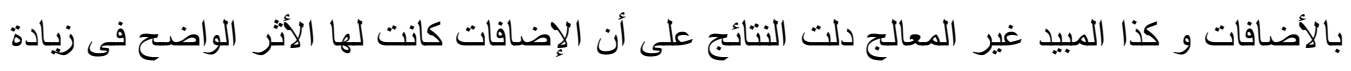

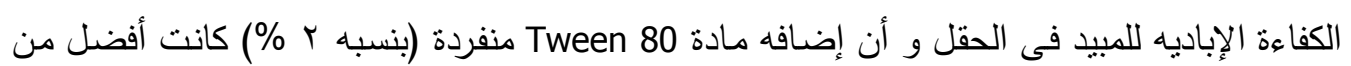
أضافه مخلوطها مع المذيب العضوى DMF بنفس النسبه. 